NASA Technical Memorandum 87670

NASA-TM-8767019860010086

APPLICATION OF CFD TO AEROTHERMAL HEATING PROBLEMS

MICHELE G. MACARAEG

\section{FOR REFERENCE}

Langley Research Center Hampton, Virginia 23665

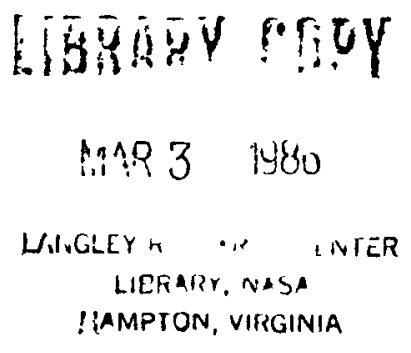

I:AMPTON, VIFRGINIA
NกSก

National Aeronautics and National Aeronautics
Space Administration
NF01251

HOT TO BE TAKEN FHOM TUIS MOON 


\title{
APPLICATION OF CFD TO AEROTHERMAL HEATING PROBLEMS
}

\author{
M. G. Macaraeg* \\ NASA Langley Research Center \\ Hampton, Virginia
}

\section{Abstract}

Numerical solutions of the compressible Navier-Stokes equations by an Alternating Direction Implicit scheme, applied to two experimental investigations at NASA Langley Research Center are presented. The first is cooling by injection of a gas jet through the nose of an ogive-cone, and the second is the aerothermal environment in the gap formed by the wing and elevon section of a test model of the Space Shuttle. The simulations demonstrate that accurate pressure calculations are easily obtained on a coarse grid, with convergence being obtained after the residual reduces by four orders of magnitude. However, accurate heating rates require a fine grid solution, with convergence requiring at least a reduction of six orders of magnitude in the residual. The effect of artificial dissipation on numerical results is also assessed.

\section{Introduction}

In recent years an increased interest in hypersonic vehicle concepts has brought a number of aerodynamic problems for hypersonic flow into prominence. These problems are characterized by high-temperature high-velocity flows with strong viscous interactions such as shock waves, blunt leading edges, etc. A dominant feature of these flows is the aerodynamically induced high heat transfer rates to the vehicle surfaces. Accurate heat transfer rates are difficult to obtain numerically, and difficult to measure experimentally. However, accurate heating rates are important when designing a given structure and assessing its reliability.

Numerical and experimental models are important tools for understanding the aerothermal environment in high-speed flows. However, before extrapolating the results of such models to actual flight conditions careful model validation along with an understanding of the effects model assumptions have on the simulated physics are important first steps.

This paper will present results from numerical models of two experiments investigated at NASA Langley Research Center. 1 The studies were undertaken to complement experimental results by providing detailed information not obtainable experimentally. In addition, these studies assess the effects artificial dissipation, convergence criteria, and degree of resolution have on pressure and heating rate predictions, and hence provide guidelines for improved techniques. The solution technique is a second-order accurate Beam and Warming Alternating Direction Implicit (ADI) algorithm.2 The algorithm is augmented to include an explicit blend of second and fourth differences for the dissipative terms. 3

*Research Scientist, Aerothermal Loads Branch, Loads and Aeroelasticity Division, Member AIAA
The first problem is Mach 6.7 flow over a gas jet cooled ogive-cone (gas jet nose tip, GJNT; see Fig. 1a). Protecting a nose tip from severe thermal and pressure environments is an important concern for advanced entry vehicles. Very little experimental or numerical results exist for high enthalpy hypersonic flow conditions for GJNT on large cones. Therefore, a test program was conductd in the Langley 8-Foot High Temperature Tunnel $\left(8^{\prime}{ }^{\prime} \mathrm{HTT}\right)$ to study mass addition cooling by GJNT. 4,5 Numerical shock stand-off distances, pressures and cold wall heating rates will be compared to experimental results.

The second problem studied in only a preliminary fashion, is the determination of the flu$i d /$ thermal environment in the cove between the Space Shuttle wing and elevon surfaces (Fig. 1b) which has been a concern throughout the design and initial operational phases of the vehicle. If the seals at the elevon hinge line leak, hot boundary layer gas flowing into the cove will endanger the thermally unprotected inner wing and elevon structures. Previous attempt using finite difference techniques ${ }^{6}$ were unable to obtain quantitative results, possibly due to difficulties encountered with modelling the complex geometry. Finite element techniques have handled the geometric complexity and solutions have been obtained for both incompressible flow in the cove on $1 y^{7}$ and for inviscid flow for the external and internal flow fields.8 However, since details of the flow at the mouth and internal to the cove will be dominated by viscous effects and the shear layer emanating from the rear of the wing panel a full Navier-Stokes solution is required. The numerical analysis to be given models the flow with the viscous-compressible Navier-Stokes equations. Comparison of results with data from a full scale model for the wing-elevon cove tested in the $8^{\prime} \mathrm{HTT}^{9}$ is also given.

\section{Numerical Model}

The basic equations governing the flow of a viscous compressible fluid are the Navier-Stokes equations. 10 These equations, expressed in terms of a two-dimensional or axisymmetric curvilinear coordinate system, are written in strong conservative form for a perfect gas as follows:

$U_{t}+E_{\xi}+F_{\eta}+j H=m\left(R_{\xi}+S_{\eta}+j T\right) / R e$

with

$$
\begin{aligned}
& U=\bar{U} / J \\
& E=\left(\xi_{t} \bar{U}+\xi_{x} \bar{E}+\xi_{y} \bar{F}\right) / J \\
& F=\left(\eta_{t} \bar{U}+\eta_{x} \bar{E}+\eta_{y} \bar{F}\right) / J \\
& H=(\bar{F}+\bar{H}) /(y J) \\
& R=\left(\xi_{x} \vec{R}+\xi_{y} \bar{S}\right) / J \\
& S=\left(\eta_{x} \bar{R}+\eta_{y} \bar{S}\right) / J \\
& T=(\bar{S}+\bar{T}) /\left(y_{J}\right)
\end{aligned}
$$

where $\bar{U}, \bar{E}, \bar{F}, \bar{H}, \bar{R}, \bar{S}$, and $\bar{T}$ are the following four-component vectors: 


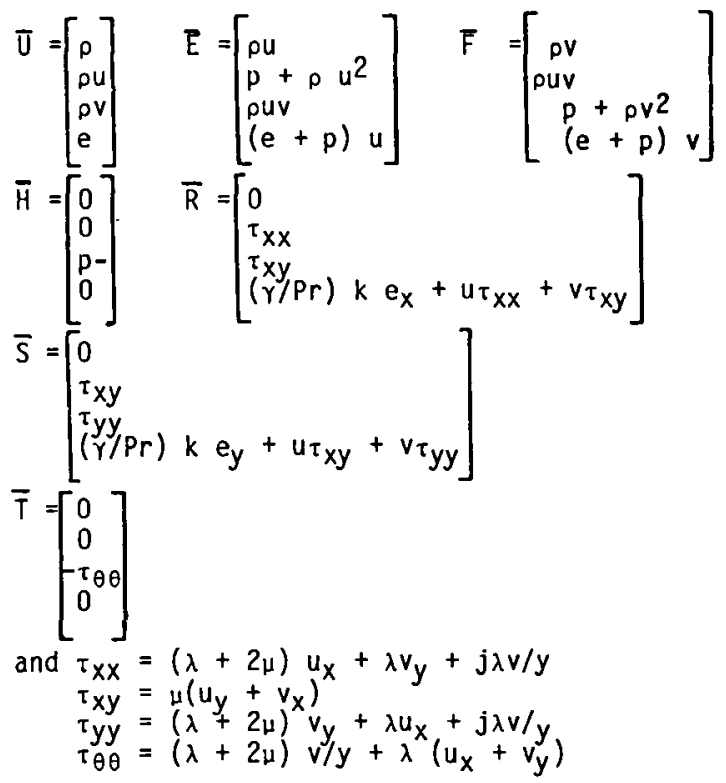

In these equations, $\xi$ and $n$ are the computational coordinates, $t$ is the time and $J$ is the Jacobian of the coordinate transformation. The computational coordinates are related to Cartesian coordinates through the coordinate transformation

$\xi=\xi(t, x, y)$

$n=n(t, x, y)$

(For generality the coordinates are written as a function of time though the cases which follow are steady-state.) In Eq. (1) $j=0$ for two- dimensional flow, $j=1$ for axisymmetric flow (y becomes the cylindrical radius), $m=0$ for inviscid flow, and $m=1$ for viscous flow.

In the conservative variables of $\mathrm{Eq}$. (1), density, velocities, and temperature are nondimensionalized with respect to freestream values. The pressure, density, and velocity components are related to the total energy per unit volume, e, by the following equation for an ideal gas:

$e=\rho\left[\bar{e}+\left(u^{2}+v^{2}\right) / 2\right]=p /(\gamma-1)+\rho\left(u^{2}+v^{2}\right) / 2$

Re represents the Reynolds number. The Prandt 1 number, $\mathrm{Pr}$, the coefficient of thermal conductivity, $k$, and the ratio of specific heats, $\gamma$, are held constant. The coefficient of thermal conductivity and the viscosity coefficient are nondimensionalized with respect to their freestream values. The viscosity coefficients, $\mu$ and $\lambda$, are computed from Sutherland's equation and Stokes' hypothesis, respectively. 11 Boundary conditions will be discussed when a given problem is addressed.

The solution technique is a second order accurate Beam and Warming ADI algorithm. The algorithin is augmented to include an explicit blend of second and fourth differences for the dissipative terms regulated by the pressure gradient in the local flow field. Their addition controls the odd-even uncoupling of grid points typical of central difference schemes, and provides strong dissipation in the region of shock waves and lesser dissipation in the remainder of the field.
All calculations were performed on the Langley Cyber 175 and took .00247sec/pt./iteration of CPU time.

\section{Gas Jet Nose-Tip}

\section{Nonblowing Cases}

Before modelling the GJNT, a series of cases for cones without gas injection were studied to assess the effects that convergence, resolution, and artificial dissipation have on numerical results without the added complications of the gas jet. Freestream conditions are $M_{\infty}=$ 6.7, $\operatorname{Re}_{\infty}=1.4 \times 10^{6} \mathrm{ft} . .^{-1}$, and $T_{\infty}=407^{\circ} \mathrm{R}$. Boundary conditions are no-slip at solid surfaces, extrapolation at outflow and a wall temperature of $540^{\circ} \mathrm{R}$.

Numerical results are compared with experimental data obtained in the Langley Research Center 8-Foot High Temperature Tunnel.12 The facility is a hypersonic blowdown wind tunnel that operates at a nominal Mach number of 7 , in a test medium of combustion products of methane and air. Numerical results will be compared with two nose configurations on a $12.5^{\circ}$ halfangle cone: a 3 inch radius tip (R3) and a one inch radius tip on an ogive frustrum (RI). Unless otherwise stated the following results and comparisons are for R1, the GJNT configuration without the jet.

Fig. 2 is a plot of shock stand-off distance comparing numerical results with experimental data. 4 As indicated in Fig. 2, standoff is measured as the distance $d_{l}$, to the body divided into the distance $\mathrm{d}_{2}$ to the bow shock. Distances are measured from the symmetry line of the body. Numerical standoff measurements are about $7 \%$ higher than experimental measurements. The impact of grid resolution on capturing this shock is illustrated in Figs. 3a and $3 b$ by Mach numbers contours. The fine grid solution has 35 points along the body and 41 normal to the body; and the coarse grid ( $17 \mathrm{x}$ 21) is obtained by deleting alternating points from the fine grid. The shock tends to steepen up towards the low Mach number side which experience has shown to be true of central difference schemes. The shock width spans three grid cells in both grids. It is interesting to note a result correlating numerical results for different gases and hemispherical bodies. 13 The correlation is a simple linear law relating shock standoff distance to the density ratio across a normal shock. Fig. $3 \mathrm{C}$ is a magnification of Fig. 3b illustrating the shock location from reference 13 and the experimental shock location at the stagnation point. The correlation predicts the shock to lie on the low Mach number side of the present numerical model. It should be noted that the numerical model of reference 13 was inviscid and adiabatic, which indicates that the shock stand-off is not a strong function of these factors.

Fig. 4 is a plot of calculated surface pressures from the fine grid after a four order of magnitude reduction in the residual, compared with experimental data. The abscissa is surface distance measured in units of nose radii. Pressures are nondimensionalized by stagnation point values. The ratio of stagnation pressure to freestream static pressure is 60.67 for the numerical model and 61.90 for the experiment. The experimental and analytical data overlap between 
three and ten inches and both are seen to fall on the same curve.

The effect of convergence criteria on pressure is illustrated in Fig. 5 which is a plot of pressure profiles from runs using coarse grids and terminated at three different average global residuals. Stagnation pressures divided by the freestream pressure for residual levels of $10^{-4}, 10^{-6}$, and $10^{-7}$ are $57.89,56.78$ and 56.77 , respectively. A four order of magnitude reduction in the residual $(2000$ iterations) differs very little from six and seven orders of magnitude reductions.

Converged solutions of pressure are used to illustrate effects of grid resolution in Fig. 6 . The ratio of stagnation pressure over freestream pressure is 56.78 for the coarse grid solution and 60.67 for the fine grid case. Differences in the two solutions for pressure are small, the discrepancy between $11 / 2$ and 2 nose radii reflect the inadequacy of the coarser grid in the tangential direction to resolve the expanding flow around the hemispherical nose.

Fig. 7 is a plot of numerically predicted pressures (residual $=10^{-6}$ ) from a coarse grid solution versus surface distance for different levels of artificial dissipation. The effect of doubling the dissipation has a noticeable effect on the pressure ratio profiles: higher dissipation resulting in higher pressure profiles. This effect illustrates the impact artificial viscosity has on the inviscid portion of the flow field where second order dissipation terms are needed to capture the bow shock. The magnitude of the dissipative terms should be kept at the minimum required to control oscillations and maintain stability of the scheme. However, determining the amount required for a particular application is typically a matter of experience 14 and dependent on the configuration, solution algorithm and dissipation model. The value of the stagnation pressure divided by the freestream pressure is 56.78 and 53.09 for the low and high dissipation cases, respectively. A comparison of calculated heating rates and experimental data, each normalized by its own stagnation point value for $\mathrm{R} 3$, is shown in Fig. 8. Since the governing equations are in nondimensional form, the ratio of heat transfers is the ratio between nondimensional temperature gradients. Experimental heating rates are nondimensionalized by stagnation point values calculated from reference 15 . The wall temperature for the Navier-Stokes calculation is fixed at $540^{\circ} \mathrm{R}$. This is the wall temperature at which the experimental data was extrapolated as a standard reduction procedure. Experimental data begin approximately three nose radii from the tip. Numerical results are seen to overlap the experimental data in this region. Fig. 9 is a similar plot for R1.

Convergence criteria are found to be more strict for heating rates than for pressures. At least a six order of magnitude reduction (5000 iterations) in the average global residual is needed to converge heating rates to a steadystate value. Fig. 10 shows heating rates converged four, six, and seven orders of magnitude. Seven orders of magnitude reduction shows almost no change from the six order of magnitude reduction. The normalization factor for all three runs are within $1.4 \%$ of each other. It should be noted that the Beam and Warming algorithm performs faster for problems with weaker shocks, though typically an order of magnitude slower than present day upwind schemes. 16 Upwind schemes, however, have not yet been tested on complicated flow fields. In addition recent work by Pulliam, 14 indicates an order of magnitude increase in convergence rate for the Beam and Warming algorithm with the addition of implicit fourth order dissipation.

The effect of grid resolution on a fine $(35 \times 41)$ and coarse $(17 \times 21)$ grid for converged heating rates is illustrated in Fig. 11. The normalization factor is $10 \%$ lower for the coarse grid solution. The disagreement is greatest between one and two nose radii from the tip. This reflects the inadequacy of the coarser grid in the tangential direction to resolve the flow expanding around the hemispherical nose.

Fig. 12 illustrates the effect doubling the dissipation has on heating rates for coarse grid solytions which are fully converged (residual = $10^{-7}$ ). The profiles are not identical; the higher dissipation resulted in lower heating rates. The lower dissipation case has a normalization factor which is $7 \%$ higher than the high dissipation case.

\section{Gas Jet Nose-Tip}

To reduce the excessive heating loads on bodies in hypersonic flow a study of the cooling effectiveness produced by mass injection was conducted in the $8^{\prime}$ HTT.4,5 A parallel study is presented using the Navier-Stokes code. Freestream conditions are $M_{\infty}=6.7, R_{\infty}=1.4$ $x 10^{6} \mathrm{ft} .-1, \gamma=1.382$, Prandt 1 number $=.743$. The gas jet has a temperature of $495^{\circ} \mathrm{R}$ and is sonic at the outlet. The total pressure of the coolant divided by the pitot pressure of the flow is 2.46 producing an underexpanded jet of coolant gas. These conditions are the same as tunnel test conditions. However the experiment is in a test medium of combustion products of methane and air and the gas jet is nitrogen, while the numerical model assumes perfect gas relations and ignores molecular diffusion. Numerical results are obtained on a $35 \times 41$ grid ( 35 points along the body and 41 normal to the body) and residuals are reduced by 6 orders of magnitude.

In 1965 GJNT experiments conducted by Finley 17 on a blunter body led him to postulate flow features based on Schlieren, shadowgraph and experimental data. A schematic taken from ref. 17 is reproduced in Fig. 13. The schematic depicts a low velocity recirculation zone surrounded by a shear or mixing layer which attaches to the body beyond the recirculation zone. A comparison between GJNT experiments conducted in the $8^{\prime}$ HTT and the numerical model reveals similar features.

Fig. 14 is a qualitative comparison of shock stand-off distance by interfacing a shadowgraph from the GNNT experiment ${ }^{2}$ with Mach number contours from the numerical solution. Stand-off distance compares well with the low Mach number side of the simulated shock. (Recall from Fig. 3 that a finer grid will cause the shock to steepen up towards the low Mach number side.) Three cells span the shock width which is expected with first order accuracy in this region. A quantitative plot of shock stand-off distance versus angular distance about the symmetry line at the nozzle exit plane is given in Fig. 15. 
Fig. 16 is a plot of temperature contours $\left(T_{W}=540^{\circ} \mathrm{R}\right)$ which helps illustrate some important flow features. The distance indicated as $s=4.0$ inches (axial) encompasses a recirculation region, as confirmed by numerical values of velocities, where the cold gas is most effective in cooling the body. Downstream of this recirculation zone, at approximately four inches from the nose tip, flow reattaches and the temperature contours move in toward the body though a cold layer of gas still persists down the length of the body. Heating rates remain negative outside the recirculation region, but increase after the recirculation zone. Some of these same features are revealed by image enhancements of experimental photographs. Fig. 17 is an image enhancement of a Schlieren taken of a GJNT experiment. 5 The contrasts help delineate the recirculation region and an outer mixing layer of hot incoming gas mixing with the jet and impinging the body downstream of this recirculation zone. Fig. 18 is a composite of two enhancements of the shadowgraph in Fig. 14. It shows further detail of the recirculating gas jet and depicts a turbulent mixing layer outside the recirculation region. Experimental heat transfer data also indicates turbulent mixing to be occurring. These observations are not surprising since the Reynolds number of the gas jet based on the nozzle diameter is approximately 2 $x 10^{6}$, which is three orders of magnitude higher than the Reynolds number for fullydeveloped turbulent pipe flow. Fig. 19 is a comparison of numerical and experimental heating rates. These heating rates are nondimensionalized by stagnation point values of a nonblowing experimental case. The heating in the numerical model is due to lateral conduction as expected in a laminar flow. The experimental data show high positive heating rates downstream of the recirculation zone indicating turbulent mixing of the hot incoming gas with the turbulent gas jet. Note that experimental heating rates radically increase at approximately four inches from the nose tip, which is the length of the recirculation region indicated in the temperature contour plot of Fig. 16. However, the numerical heating rates remain negative downstream of the recirculation zone. The numerical results for the adiabatic wall case show wall temperatures below $540^{\circ} \mathrm{R}$ which confirm the negative heating rates in Fig. 19 . Fig. 20 is a plot of adiabatic wall temperatures for a cold gas jet $\left(495^{\circ} R\right)$ and a slightly warmer gas $\left(540^{\circ} \mathrm{R}\right)$. The adiabatic temperatures are well below the fixed cold wall temperature, the warmer gas having slightly higher adiabatic temperatures. As expected a warmer gas results in higher heating rates as shown in Fig. 21 , which plots heating rates for gas jets of $495^{\circ} R$ and $800^{\circ}$. Figs. 20 and 21 reveal that differences in gas jet temperatures are not sufficient to account for the discrepancy between numerical and experimental heat transfer since the increase in heating rates is small for a $395^{\circ}$ rise in gas jet temperatures. Thus, the numerical comparison with experiment suggests that maintaining the gas jet as laminar as possible will increase its cooling effectiveness. Comparison of experimental 4 and numerical pressures normalized by stagnation point values of a nonblowing case is given in Fig. 22. The numerical pressures indicate a dip in the recirculating region. Experimental data begin outside of this region at approximately 12 inches. The comparison indicates good agreement. A calculation of the ratio between the pressure behind the normal shock and $P_{\infty}$ for a nonblowing case is 57.702 . The highest pressure ratio in the GJNT numerical model, experienced at the lip of the ogive, is around 31 . Thus the gas jet substantially reduces the pressure load on the nose tip.

\section{Preliminary Study of a Wing-Elevon Cove}

The last problem to be addressed is a study of the fluid/thermal environment in the cove between the wing and elevon on the Space Shuttle (Fig. 1b). The gap between the Space Shuttle wing and elevon surface is closed by seals at the elevon hinge line to prevent the leakage of hot boundary layer gases. If these hot gases flow into the cove, damage to the thermally unprotected inner wing and elevon structures could occur. To provide insight into the problem a full scale model of the wing-elevon cove was tested in the $8^{\prime}$ HTT. ${ }^{9}$ A 20 Navier-Stokes solution of the aerothermal environinent of the wing elevon cove is given. A major difficulty in obtaining a reliable numerical solution has been producing a computational grid which models the cove geometry adequately. A fully interactive 20 algebraic grid generator ${ }^{18}$ currently under development by Erlebacher at Langley, is used to generate the grid required for the present work. Fig. 23a show the grid produced by this method, for a cove geometry in which the seal "leak" area is equal to the entrance area and the elevon deflection is $25^{\circ}$ with respect to the wing. The grid is composed of 55 points on the coordinate family which spans the cove gap, and 81 points on the opposite family. The entrance "neck" region is quite difficult to grid with adequate resolution and nearorthogonality; the enlargement of that region shown in Fig. 23b shows good performance by the above procedure.

In the experimental investigation of the configuration, the elevon/gap apparatus was mounted in a flat test bed inserted into the tunnel; a flat run of approximately 48 inches preceded the cove entrance. The entire test bed was inclined $5^{\circ}$ (compression) with respect to freestream. The tunnel freestream conditions were $M_{\infty}=6.7, R_{\infty}=1.0 \times 10^{6} \mathrm{ft}^{-1}$ and $T_{\infty}=399^{\circ} \mathrm{R}$; the Reynolds number based on cove entrance gap was 115,000 .

Upstream inflow conditions were difficult to set in the numerical model, since the inclination of the experimental apparatus resulted in a weak shock, with a slight entropy layer due to the small radius $\left(3 / 8^{\prime \prime}\right)$ leading edge. Since no detailed surveys of the flowfield upstream of the cove were available, numerical inflow conditions were approximated by setting tunnel freestream conditions inclined at $5^{\circ}$ to the wing surface, blending into a flatplate boundary layer profile near the wing surface. The thickness of the boundary layer was about $20 \%$ of the cove entrance gap, consistent with the flat plate run preceding the cove entrance in the experimental apparatus. The effect of these approximate inflow conditions requires further assessment. No-slip, flow tangency and zero normal-pressure gradient were 
imposed on the wing and elevon surfaces, along with either adiabatic (zero normal-temperature gradient) or constant wall temperature $\left(540^{\circ} \mathrm{R}\right)$ conditions. Extrapolation was used at both freestream outflow and cove "leak" regions.

Fig. 24 is a Mach number contour plot of the flow in the wing-elevon cove. Note the weak compression waves upstream of the cove entrance due to the $5^{\circ}$ angle of the input conditions as mentioned previously. Since in the experiment the leading edge is 48 inches from the cove entrance the compression waves did not have a comparable impact on the flow in the near vicinity of the cove entrance. The boundary layer separates from the wing trailing edge forming a shear layer across the cove entrance which impinges on the deflected elevon downstream where the elevon shock forms. Separation occurs just upstream of the cluster of flow direction arrows at the wing trailing-edge in Fig. 25 indicating a reversal of flow direction. On the cove side of the shear layer a large primary recirculation region forms and flow is directed into the cove. A small secondary recirculating area appears on the elevon surface inside of the cove. In Fig. 25 this secondary vortex is seen as the flow initially heads up the cove and then abruptly reverses direction in a confined region above the recirculation. The primary recirculation is quite strong; local Mach numbers exceed one in some areas. However, little flow is induced farther up in the cove, where Mach numbers are less than . 3 .

Comparisons are made with experimental data in Fig. 26 for the pressure coefficient $C_{p}$ versus surface distance. As indicated in Fig. 23a measurements begin at 0 in the cove and proceed down the elevon surface. Numerical values of $C_{p}$ are higher than experimental data. The prediction of the slope for the steep $C_{p}$ rise is higher than the experiment. This rise occurs where the shear layer merges with the shock. The occurrence of transition in this separated shear layer is likely to influence the value of this gradient. Experimental results for this test case ${ }^{9}$ indicate heat transfer data on the elevon to be within a factor of two of fully turbulent flow as calculated by a reference enthalpy method, thus suggesting the likelihood that this separated shear layer is indeed in transition. It should be noted that a similar effect might occur if the experimental boundary layer was substantially thicker than the one assumed in this analysis, (the lower velocities causing lower pressure recovery on the elevon and a longer distance before the inviscid level is obtained.)

The value of the $c_{p}$ (i.e. pressure) plateau on the elevon is within a few percent of the experimental value verifying proper post shock inviscid conditions in the numerical mode? The dip in $C_{p}$ at approximately 7.5 inches is at the attachment point. There are not enough experimental data points to plot a profile in this section.

\section{Conclusions}

Two aerothermal flow problems of relevance in hypersonic flow research have been modelled by compressible Navier-Stokes calculations using an ADI scheme and compared with experiment. In this process, the impact of resolution, convergence and dissipation on predictẹ presșures and heating rates was assessed. Heating rates were found to require at least a six order of magnitude reduction in residual for full convergence whereas pressures were converged after a reduction of four orders of magnitude. In addition, accurate heating rate predictions required a finer grid than accurate pressure predictions. In both cases, discrepancies in the fine and coarse grid solution occurred at the stagnation point and where the flow expanded rapidly, reflecting the inadequacy of the coarse grid in the tangential direction to resolve the expansion. Doubling both the second and fourth order dissipation produced noticeable changes in both pressures and heating rates. The higher dissipation reduced predicted heat transfer rates and increased pressures. Such effects illustrate the impact artificial dissipation has not only on the boundary layer but in the inviscid portion of the flow field where the second order dissipation terms are needed to capture shocks. The ability of the Navier-Stokes/ADI scheme to model complex hypersonic flows was illustrated by comparison with experiment. A numerical model of the GJNT at zero angle of attack compared favorably with experimental pressures, shock stand-off and qualitative features. However, experimental heating rates beyond the recirculation zone were much higher than the numerical heating rates. Differences in the gas jet temperature was shown to be insufficient in the numerical model to account for the large discrepancy in the comparison. However, thenumerical model is laminar and the heating rates from the experiment may be dominated by turbulent mixing of the incoming hot gas with the turbulent gas jet. The considerably lower heating rates in the numerical model suggests that maintaining the jet as laminar as possible might greatly enhance its cooling effectiveness. Preliminary results from numerically modelling a wing-elevon cove indicate good agreement with experimental values of $C_{p}$ and qualitative flow features. An over prediction by the numerical model in the magnitude of a steep $C_{p}$ gradient occurring in the vicinity of the separated shear layer may be due to transition effects in the experimental model, since experimental results indicate heat transfer data on the elevon to be within a factor of two of fully turbulent flow. In addition numerical inflow conditions were approximations to the conditions present in the experimental model; the effect of proper inflow conditions requires further assessment. However, the value of the $C_{p}$ plateau after its steep rise, predicted by the numerical model is within a few percent of the experimental value verifying the proper post-shock inviscid conditions in the numerical model. Agreement with experimental data in both cases would be greatly enhanced by including turbulence and real gas effects in the numerical model.

For complicated flow fields Beam and Warming is a proven algorithm in performance and reliability. Present day upwind schemes have not yet been tested for complex flow fields, though for simpler problems upwind schemes do exhibit an order of magnitude faster convergence rate than Beam and Warming. However, recent work by Pulliam indicates an order of magnitude increase in speed after the addition of implicit fourth order dissipation to the Beam and Warming algorithm, which would make it competitive with upwind methods. 


\section{References}

1. Gardner, J. E., and Dixon, S. C.: "Loads and Aeroelasticity Division Research and Technology Accomplishments for FY 1983 and Plans for FY 1984," NASA TM 85740, 1984.

2. Beam, R. M., and Warming, R. F.: "An Implicit Factored Scheme for the Compressible Navier-Stokes Equations," AIAA Journal, Vol. 16, No. 4, April 1976.

3. Jameson, A.; Schmidt, W.; and Turkel, E.: "Numerical Solution of the Euler Equations by Finite Volume Methods Using Runge-Kutta Time-Stepping Schemes," AIAA 14th Fluid and Plasma Dynamics Conference, June 1981.

4. Nowak, R. J.: "Gas Jet and Tangent Slot Film Cooling Tests of a $12.5^{\circ}$ Cone at Mach 6.7," NASA TP, 1986.

5. Puster, R. L.: Aerothermal Loads Branch, Loads and Aeroelasticity Division, NASA Langley Research Center, private communication.

6. Wieting, A. R.; Walsh, J. L.; and Bey, K. S.: "Aerothermal Environment in Control Surface Gaps in Hypersonic Flow - An Overview," AIAA-83-1483, AIAA 18th Thermophysics Conference, Montreal, Canada, June 1983.

7. Bey, K. S.: "Analytical Prediction of Aerothermal Environment in a Wing-Elevon Cove," NASA TM 85711, November 1983.

8. Bey, K. S.; Thornton, E. A.; Dechaumphai, P.; and Ramakrishnan, R.: "A New Finite Element Approach for Prediction of Aerothermal Loads - Progress in Inviscid Flow Computations," AIAA Paper No. 85-1533-CP, 7th AIAA Computational Fluid Dynmaics Conference, July 1985.

9. Deveikis, W. D.: "Effects of Flow Separation and Cove Leakage on Pressure and Heat-Transfer Distributions Along a Wing-Cove-Elevon Configuration at Mach $6.9, "$ NASA TP 2127, July 1983.

10. Kutler, P.; Chakravarthy, S. R.; and Lombard, C. K.: "Supersonic Flow Over Ablated Nosetips Using an Unsteady Implicit Numerical, Implicit Numerical Procedure," AIAA Paper No. 78-213, AIAA 16th Aerospace Sciences Meeting, Huntsville, AL, 1978.

11. "Equations, Tables, and Charts for Compressible Flow," NACA Report 1135 Ames Research Staff, 1953.

12. Nowak, R. J.; Albertson, C. W.; and Hunt, L. R.: "Aerothermal Tests of a 12.5 Cone at Mach 6.7 for Various Reynolds Numbers, Angles of Attack, and Nose Shapes," NASA TP 2345, January 1983.

13. Inouye, E.: "Shock Stand-Off Distance for Equilibrium Flow Around Hemispheres obtained from Numerical Calculations," AIAA Journal, Vol. 3, No.1, Jan. 1965.
14. Pulliam, T. H.: "Euler and Thin Layer Navier-Stokes Codes: ARC2D, ARC3D," Computational Fluid Dynmaics User's Workshop, The University of Tennessee Space Institute, March 1984.

15. Fay, J. A.; and Riddell, F. R.: "Theory of Stagnation Point theat Transfer in Dissociated Air," Journal of Aeronautics Science, Vol. 25, No. 2, Feb. 1958.

16. Walters, R. W. and Dwoyer, D. L.: "An Efficient Iteration Strategy Based on Upwind/Relaxation Schemes for the Euler Equations," AIAA-85-1529-CP, AIAA 7th CFD Conference, $\mathrm{OH}, \mathrm{July} 1985$.

17. Finley, P. J.: "The Flow of a Jet from a Body Opposing a Supersonic Free Stream," Journal of Fluid Mechanics, Vol. 26, part 2, 1966.

18. Eiseman, P. R.: "Alternating Direction Adaptive Grid Generation," AIAA 6th Computational Fluid Dynamic Conference," 1983.
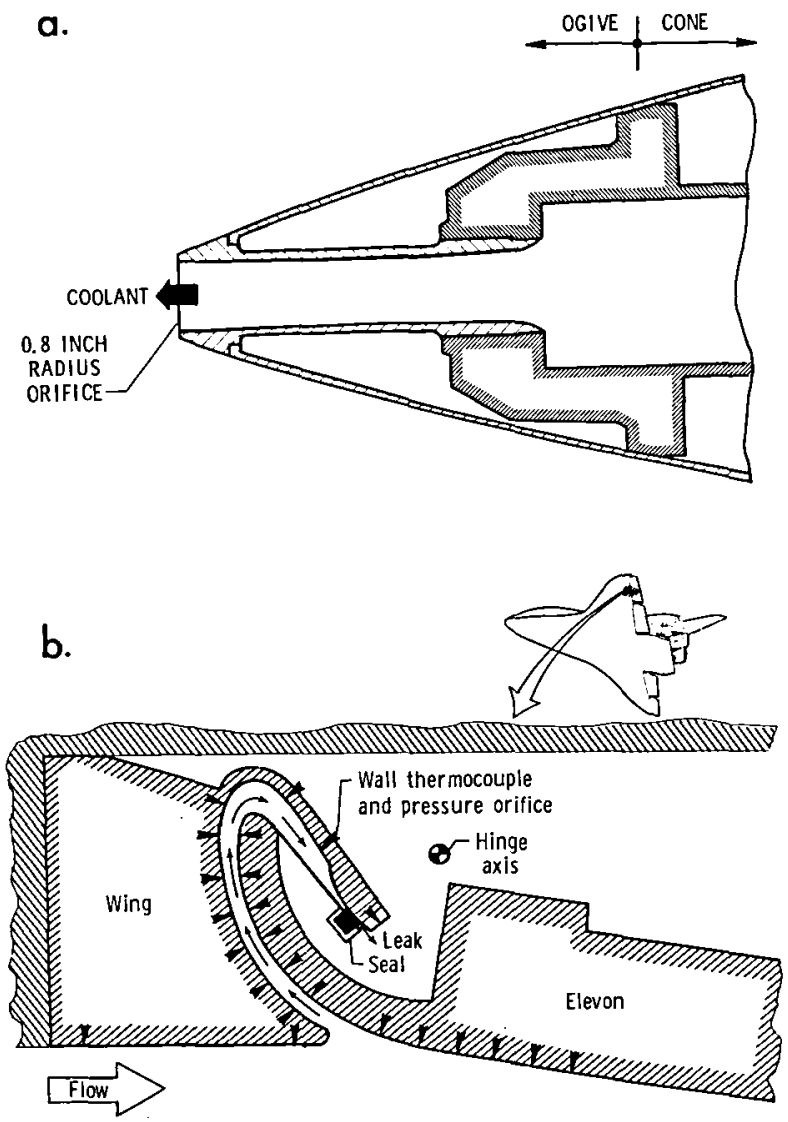

Fig. 1. Tests in the 8-Foot High Temperature tunnel at NASA Langley Research Center a) gas jet nose-tip ogive-cone b) wing-elevon cove 


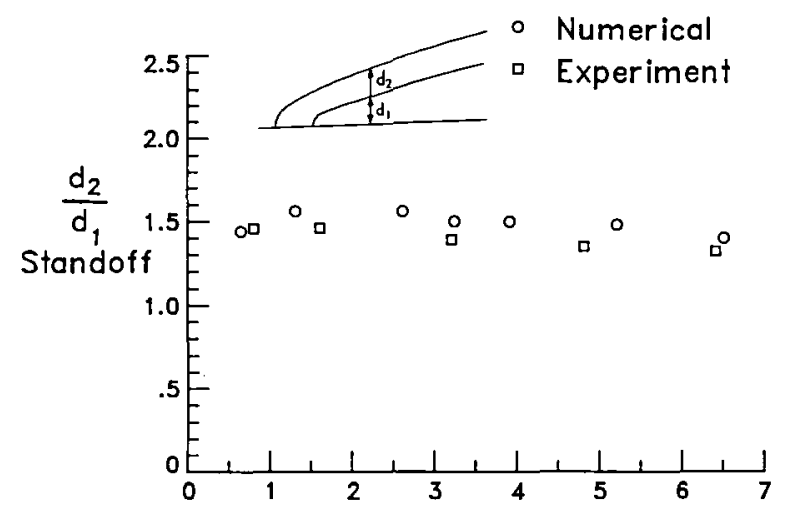

Axial Distance

Fig. 2. Shock Stand-Off Comparison on Nonblowing Ogive-Cone (R1): Numerical and Experimental Results

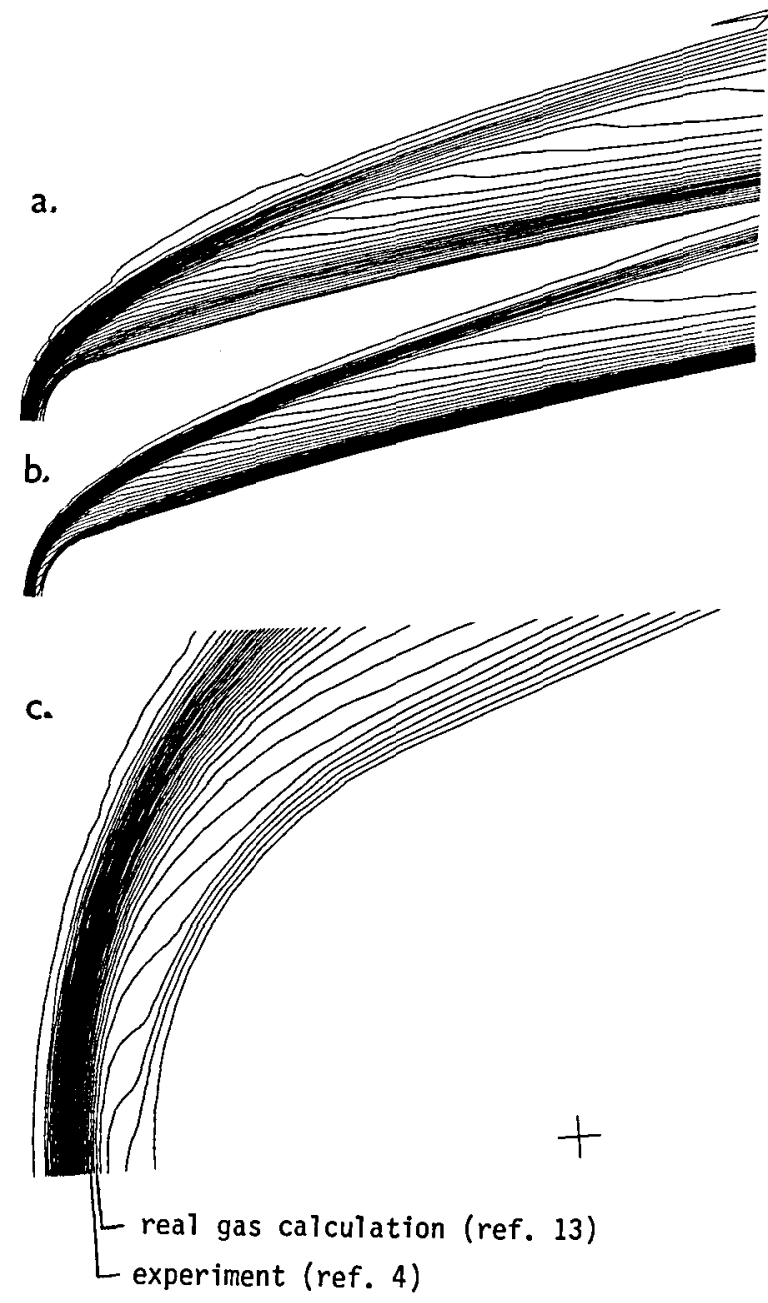

Fig. 3. Coarse and Fine Grid Solution for R1: Comparison of Shock Stand-Off Distance a) coarse grid solution

b) fine grid solution

c) magnification of fine grid solution

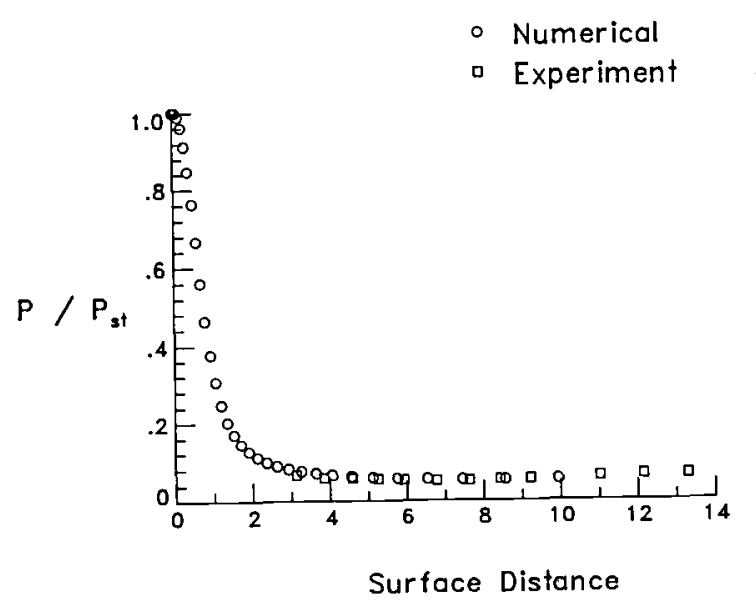

Fig. 4. Calculated and Experimental Pressures for Nonblowing Case (R1)

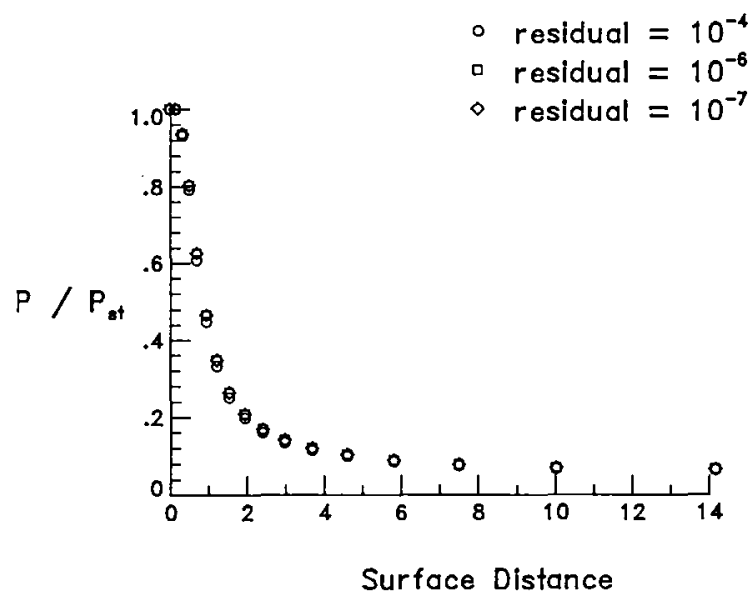

Fig. 5. Effect of Convergence on Pressures (R1)

- Coarse grid

- Fine grid

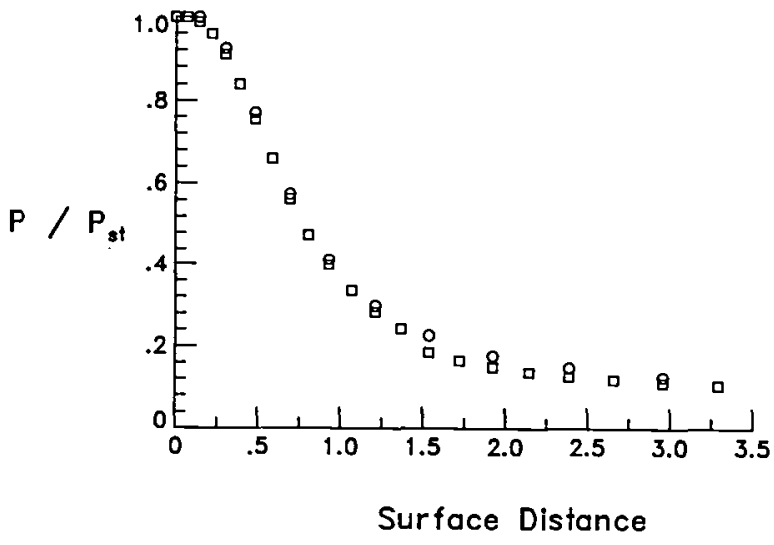

Fig. 6. Coarse and Fine Grid Solution of Pressures (R1) 


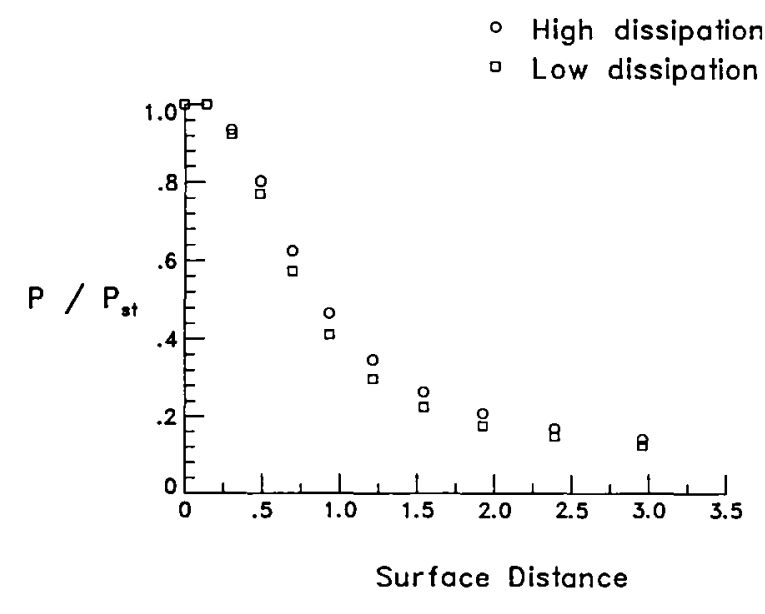

Fig. 7. Effects of Dissipation on Pressure

(R1)

- Numerical

- Experiment

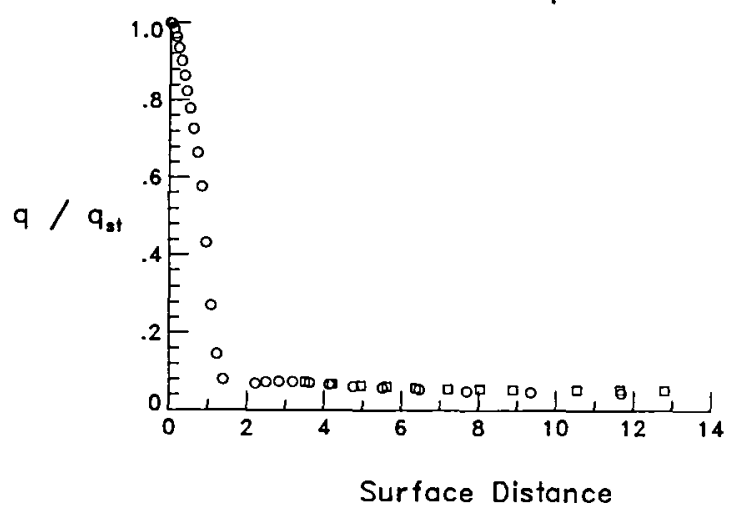

Fig. 8. Calculated and Experimental Heating Rates for Nonblowing Cone (R3)

- Numerical

- Experiment

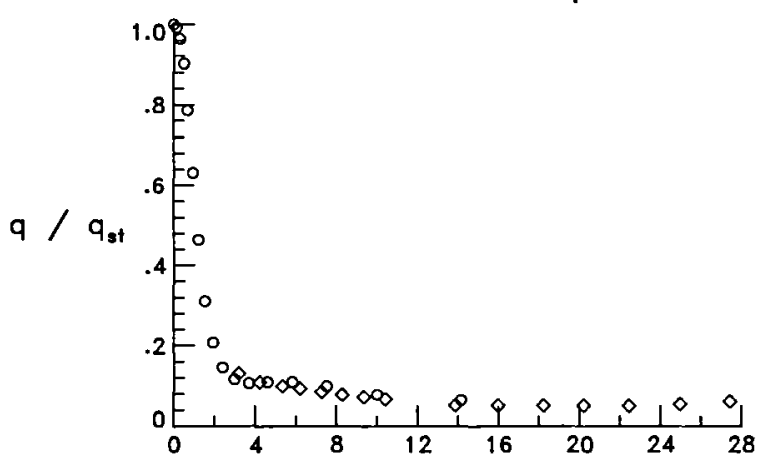

Surface Distance

Fig. 9. Calculated and Experimental Heating Rates for Nonblowing Ogive-Cone (R1)

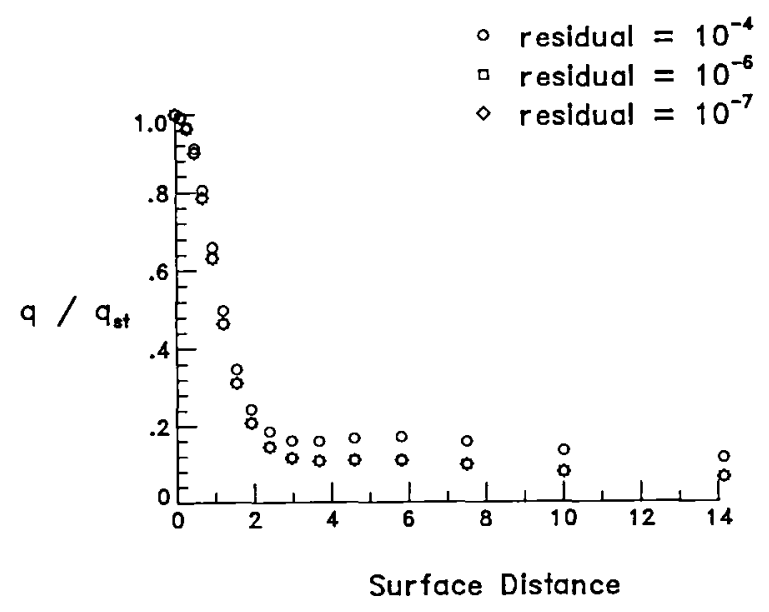

Fig. 10. Effect of Convergence on Heating Rates (R1)

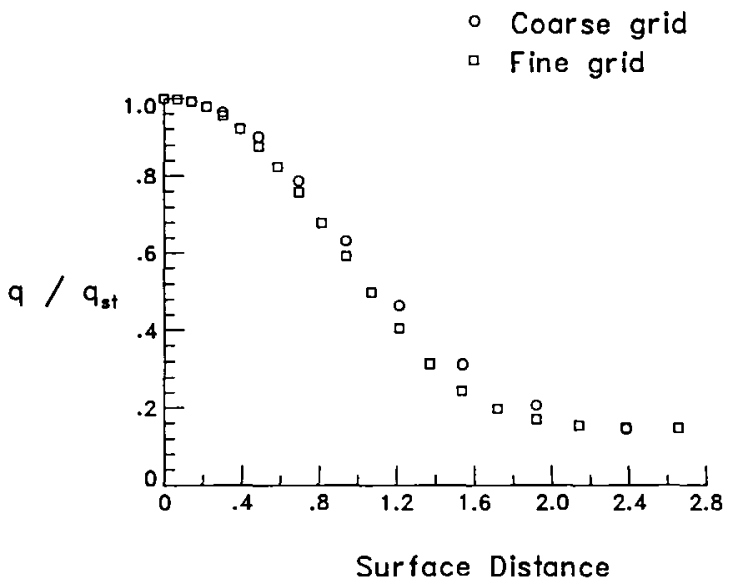

Fig. 11. Coarse and Fine Grid Solution of Heating Rates (R1)

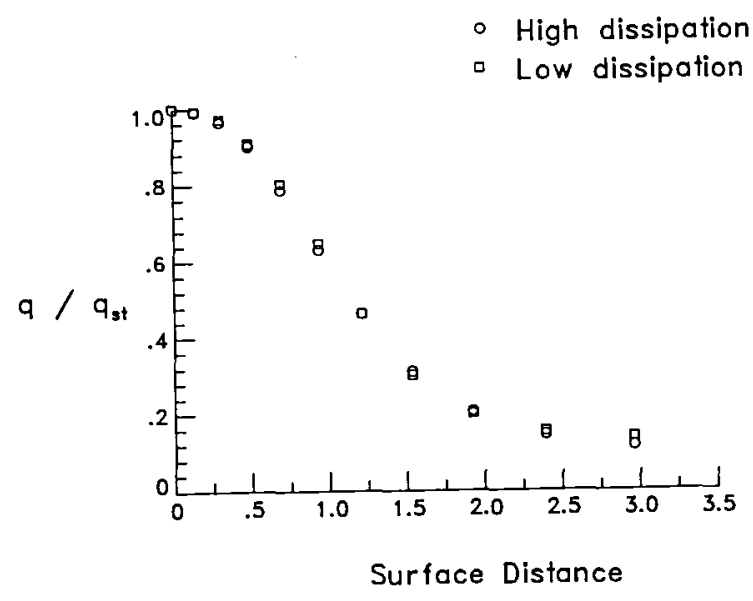

Fig. 12. Effect of Dissipation on Heating Rates (R1) 

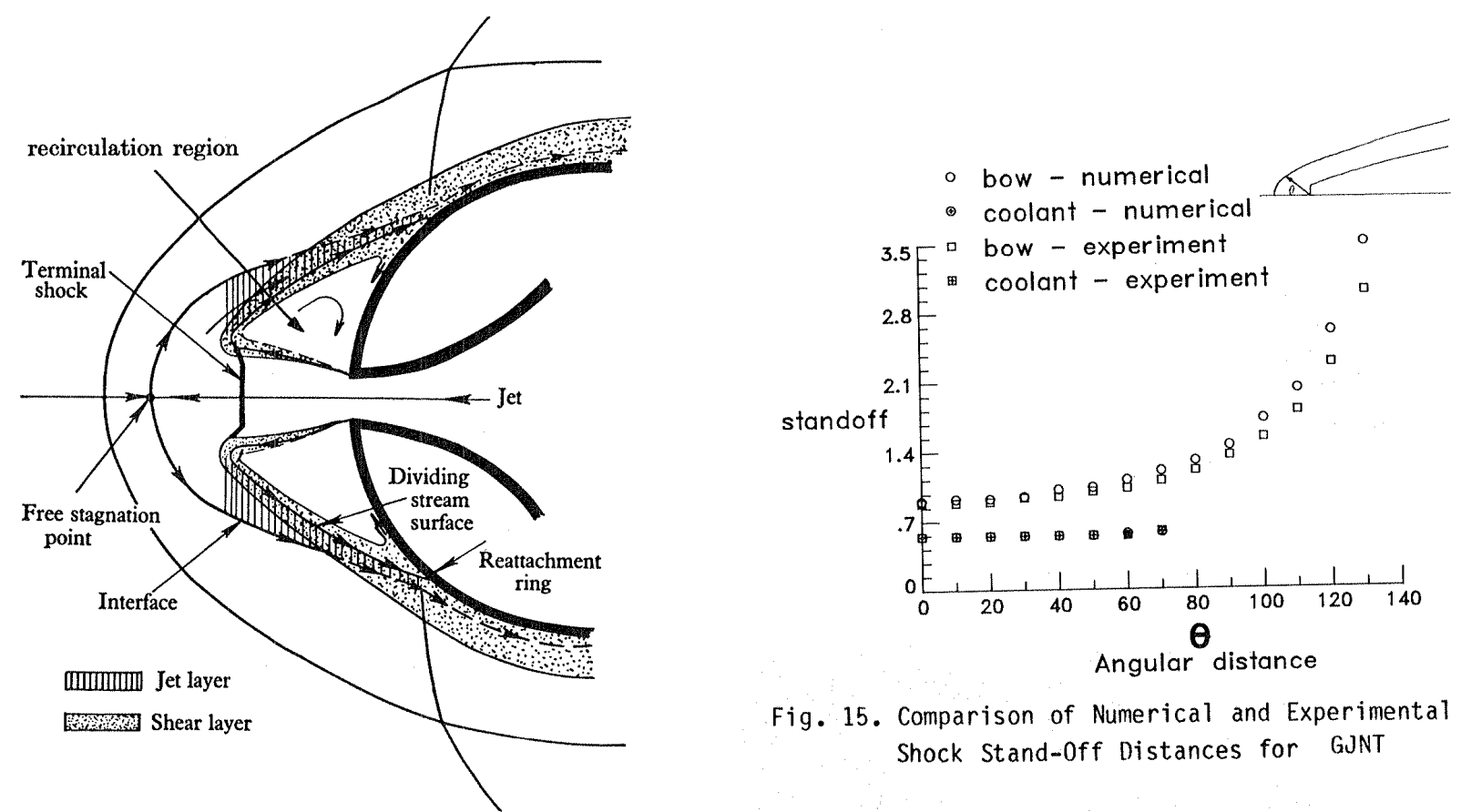

Fig. 15. Comparison of Numerical and Experimental Shock Stand-0ff Distances for GJNT

Fig. 13. Features of a GJNT Flowfield (ref. 17)

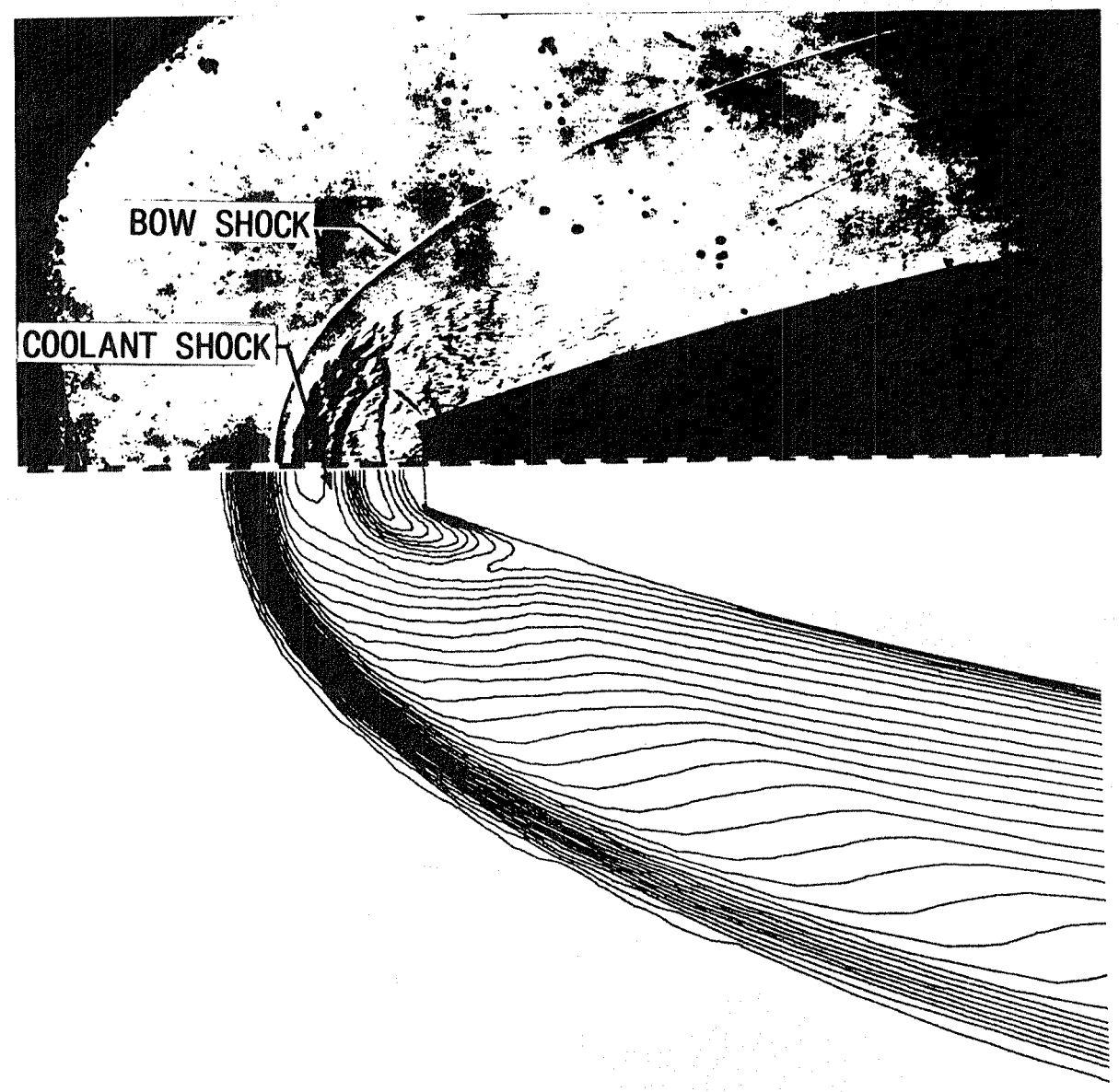

Fig. 14. Qualitative Comparison of Numerical and Experimental Models of the GJNT 


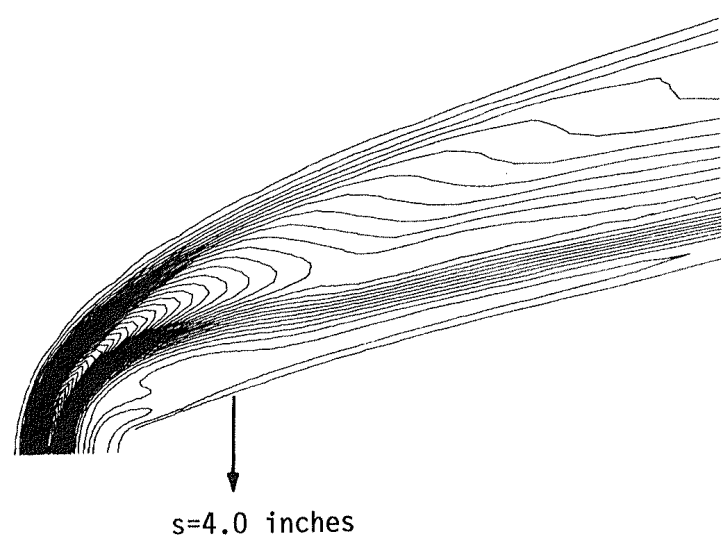

Fig. 16. Temperature Contour Plot of GJNT

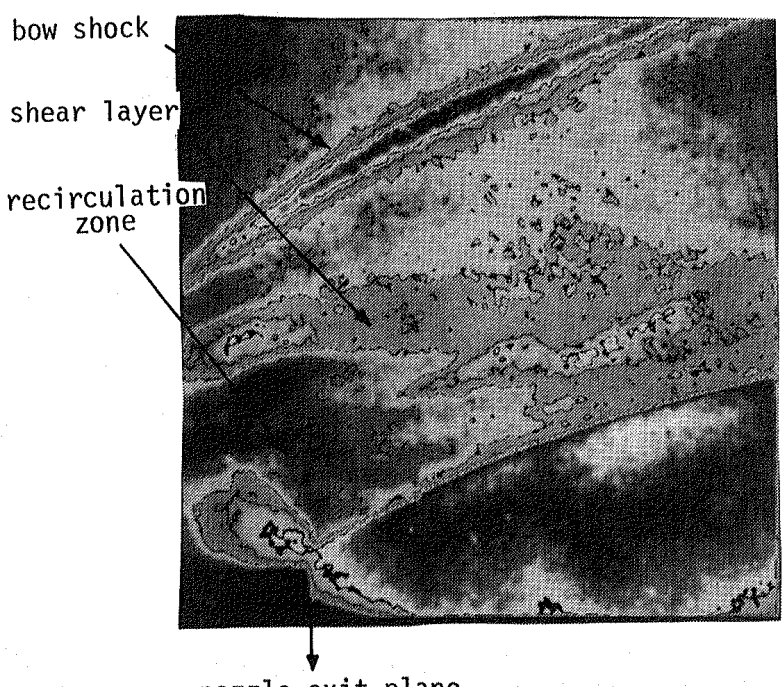

Fig. 17. Image Enhancement of GJNT Schlieren

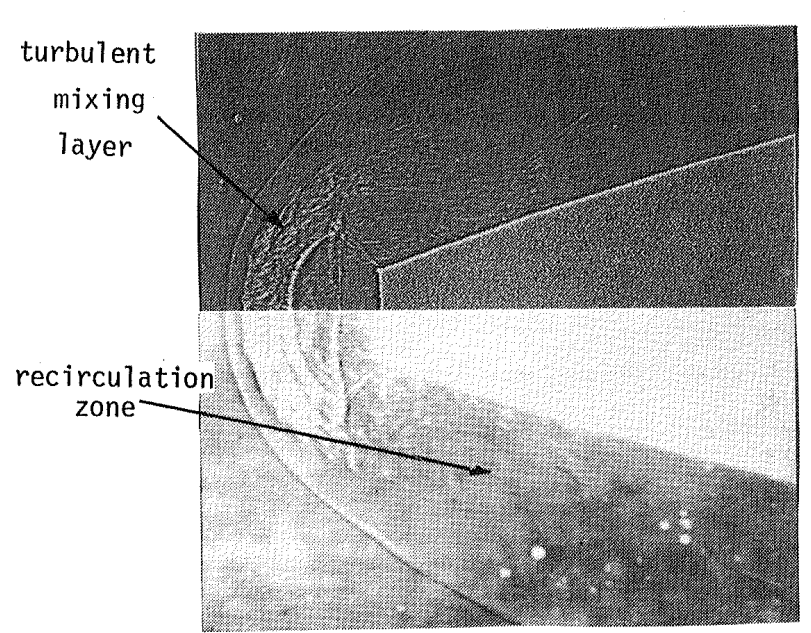

Fig. 18. Image Enhancement of GJNT Shadowgraph

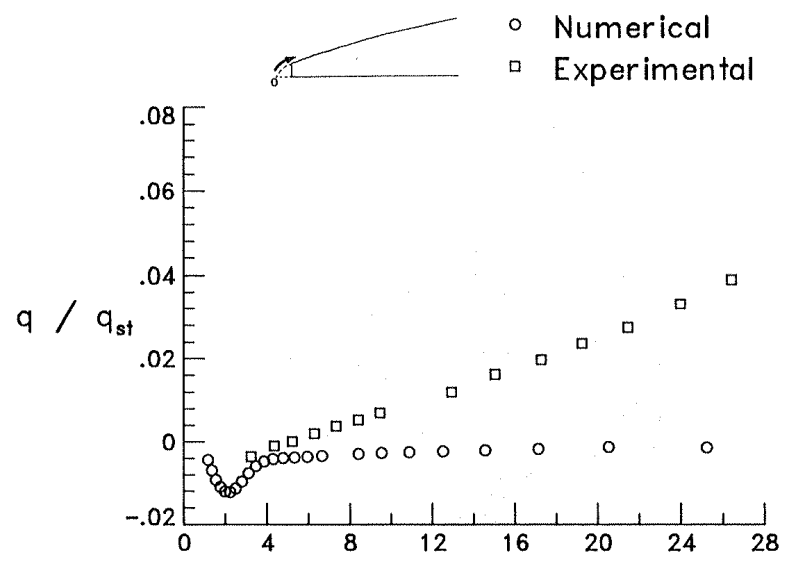

Surface Distance

Fig. 19. Calculated and Experimental Cold Wa1l Heating Rates for GJNT

$$
\begin{aligned}
\circ T_{\text {gas }} & =540 \\
\square \quad T_{\text {gas }} & =495
\end{aligned}
$$

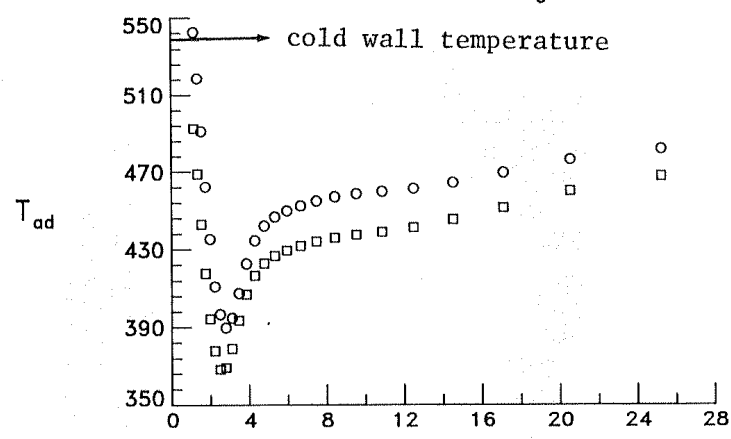

Surface Distance

Fig. 20. Calculated Adiabatic Temperatures for GJNT

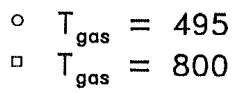

$\mathrm{q} / \mathrm{q}_{\mathrm{st}}{ }^{.01}$

$\therefore \quad T_{\text {gas }}=800$

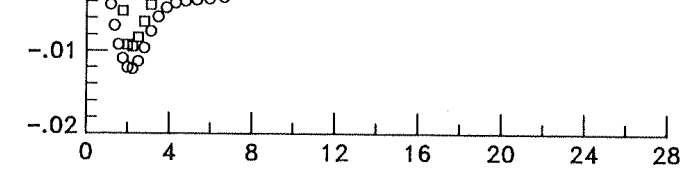

Surface Distance 
- Numerical

- Experiment

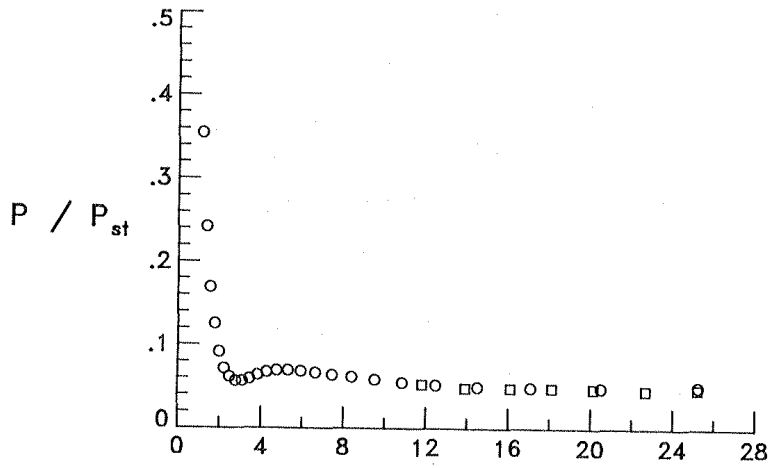

Surface Distance

Fig. 22. Calculated and Experimental Pressures for GJNT

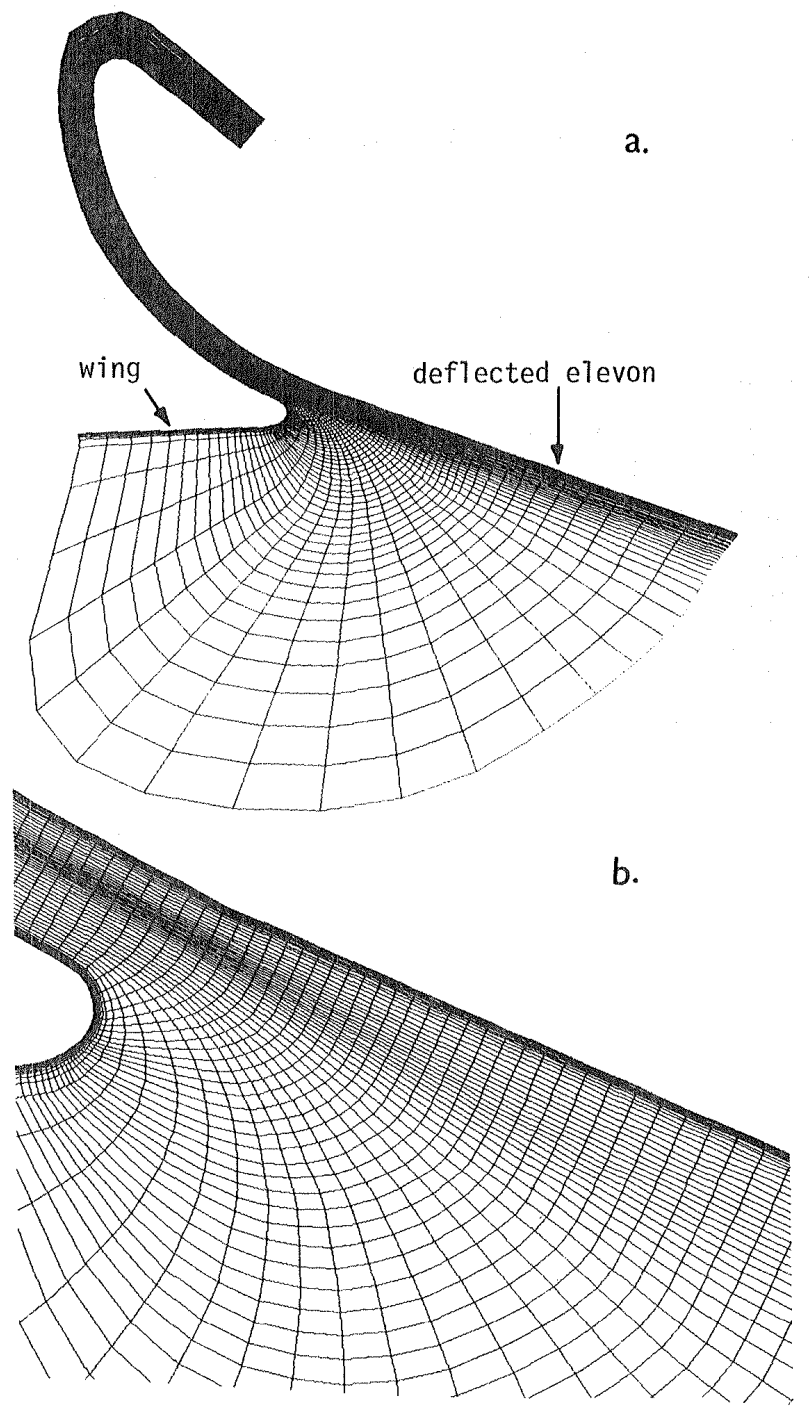

Fig. 23. Grid System for Wing-Elevon Cove Problem

a) entire computational domain

b) expanded portion of the "neck" region

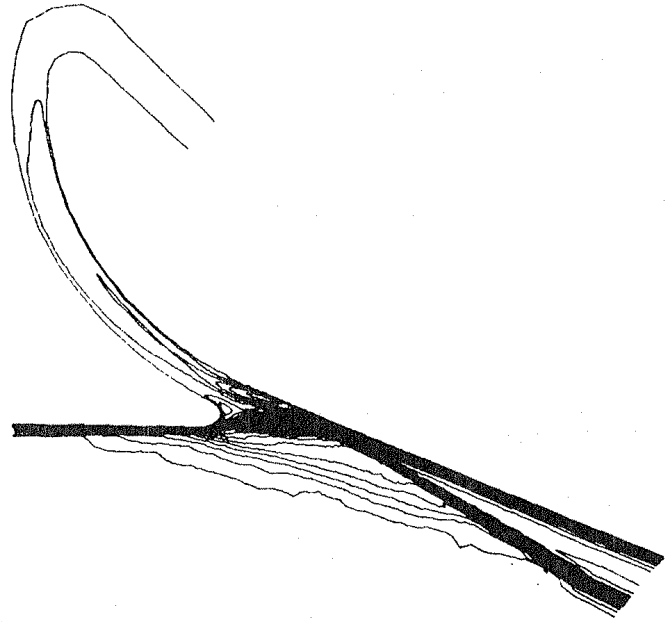

Fig. 24. Mach Number Contours of the Wing-Elevon Cove

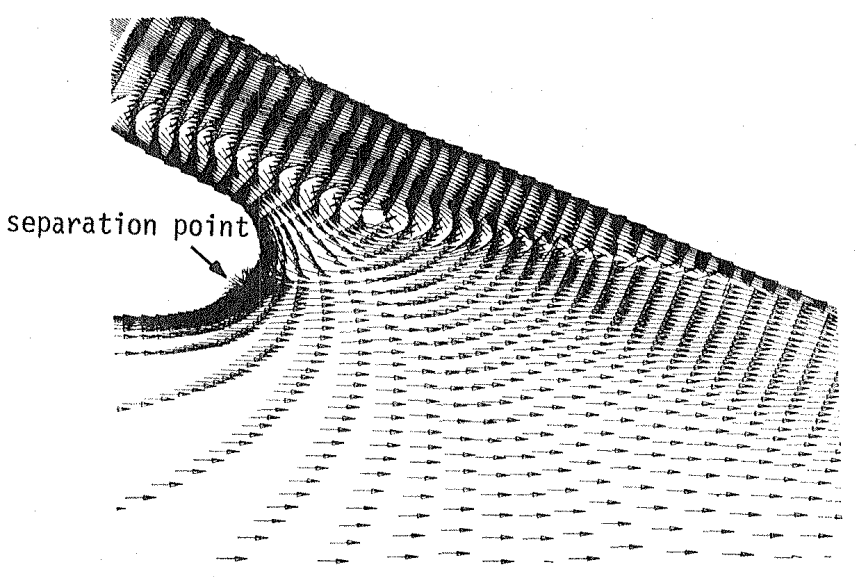

Fig. 25. Flow Direction Plot in Expanded Portion of the "Neck" Region

Numerical

- Experiment
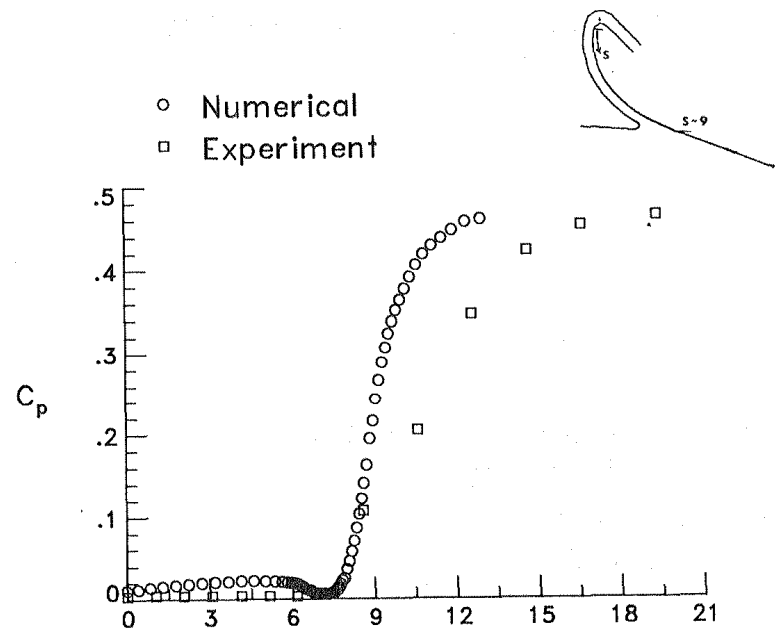

\section{Surface Distance}

Fig. 26. Calculated and Experimental Pressures for the Wing-Elevon Cove 


\begin{tabular}{|c|c|c|}
\hline $\begin{array}{l}\text { 1. Report No. } \\
\text { NASA TM-87670 }\end{array}$ & 2. Government Accession No. & 3. Recipient's Catalog No. \\
\hline \multirow{2}{*}{\multicolumn{2}{|c|}{$\begin{array}{l}\text { 4. Title and Subtitle } \\
\text { "Application of CFD to Aerothermal Heating Problems" }\end{array}$}} & $\begin{array}{l}\text { 5. Report Date } \\
\text { January } 1986\end{array}$ \\
\hline & & $\begin{array}{l}\text { 6. Performing Organization Code } \\
506-43-31-03\end{array}$ \\
\hline \multicolumn{2}{|l|}{$\begin{array}{l}\text { 7. Author(s) } \\
\text { Michele G. Macaraeg }\end{array}$} & 8. Performing Organization Report No. \\
\hline \multicolumn{2}{|l|}{ 9. Performing Organization Name and Address } & 10. Work Unit No. \\
\hline \multicolumn{2}{|l|}{$\begin{array}{l}\text { NASA Langley Research Center } \\
\text { Hampton, Virginia 23665-5225 }\end{array}$} & 11. Contract or Grant No. \\
\hline \multirow{2}{*}{\multicolumn{2}{|c|}{$\begin{array}{l}\text { 12. Sponsoring Agency Name and Address } \\
\text { National Aeronautics and Space Administration } \\
\text { Washington, DC } 20546\end{array}$}} & $\begin{array}{l}\text { 13. Type of Report and Period Covered } \\
\text { Technical Memorandum }\end{array}$ \\
\hline & & 14. Sponsoring Agency Code \\
\hline \multirow{2}{*}{\multicolumn{3}{|c|}{$\begin{array}{l}\text { 15. Supplementary Notes } \\
\text { This paper is to be presented at the } 24 \text { th AIAA Aerospace Sciences Meeting, } \\
\text { January } 6-9,1986 / \text { Reno, Nevada. }\end{array}$}} \\
\hline & & \\
\hline \multicolumn{3}{|c|}{$\begin{array}{l}\text { 16. Abstract } \\
\text { Numerical solutions of the compressible Navier-Stokes equations by an Alternating } \\
\text { Direction Implicit scheme, applied to two experimental investigations at NASA } \\
\text { Langley Research Center are presented. The first is cooling by injection of a gas } \\
\text { jet through the nose of an ogive-cone, and the second is the aerothermal environ- } \\
\text { ment in the gap formed by the wing and elevon section of a test model of the Space } \\
\text { Shuttle. The simulations demonstrate that accurate pressure calculations are } \\
\text { easily obtained on a coarse grid, with convergence being obtained after the } \\
\text { residual reduces by four orders of magnitude. However, accurate heating rates } \\
\text { require a fine grid solution, with convergence requiring at least a reduction of } \\
\text { six orders of magnitude in the residual. The effect of artificial dissipation on } \\
\text { numerical results is also assessed. }\end{array}$} \\
\hline \multicolumn{2}{|l|}{$\begin{array}{l}\text { 17. Key Words (Suggested by Authors(s)) } \\
\text { Aerothermodynamics } \\
\text { Hypersonic Flow } \\
\text { Heat Transfer } \\
\text { Computational Fluid Dynamics }\end{array}$} & $\begin{array}{l}\text { ment - Unlimited } \\
\text { Subject Category } 34\end{array}$ \\
\hline $\begin{array}{l}\text { 19. Security Classif.(of this report) } \\
\text { Unclassifjed }\end{array}$ & $\begin{array}{l}\text { 20. Security Classif.(of this pag } \\
\text { Unclassified }\end{array}$ & \begin{tabular}{|l|r|} 
21. No. of Pages & 22. Price \\
12 & $\mathrm{AO} 2$
\end{tabular} \\
\hline
\end{tabular}


End of Document 